Allafi \& Newbury, 2021

Volume 5 Issue 3, pp. 01-12

Received: 17 th May 2021

Revised: 27 th July 2021, 28 ${ }^{\text {th }}$ September 2021

Accepted: 30th October 2021

Date of Publication: 15 $5^{\text {th }}$ November 2021

DOI- https://doi.org/10.20319/pijtel.2021.53.0112

This paper can be cited as: Allafi, R. E Newbury, P. (2021). Importance of Assistive Mobile Applications for Dyslexic Students in Saudi Arabia. PUPIL: International Journal of Teaching, Education and Learning, 5(3), 01-12.

This work is licensed under the CreativeCommons Attribution-NonCommercial 4.0 International License. To view a copy of this license, visit http://creativecommons.org/licenses/by-nc/4.0/ or send a letter to Creative Commons, PO Box 1866, Mountain View, CA 94042, USA.

\title{
IMPORTANCE OF ASSISTIVE MOBILE APPLICATIONS FOR DYSLEXIC STUDENTS IN SAUDI ARABIA
}

\author{
Randa Saad Allafi \\ School of Engineering and Informatics, University of Sussex, Brighton, United Kingdom \\ ra480@sussex.ac.uk \\ Department of Computers and Information Technology, Northern Border University, Arar, Saudi \\ Arabia \\ randa.s.allafi@nbu.edu.sa \\ Paul Newbury \\ School of Engineering and Informatics, University of Sussex, Brighton, United Kingdom \\ p.newbury@sussex.ac.uk
}

\begin{abstract}
Worldwide, Education systems have been affected by Covid-19; therefore, mobile learning (Mlearning) has become more important in supporting flexibility and availability, leading to a clear trend in the learning process for this significant and valuable society sector. Much research has been conducted to measure the benefits of using Mobile Applications for students in general and specifically for students with learning disabilities such as dyslexia. Although a significant amount of research has discussed M-learning with dyslexic students in multiple languages, it is considered in its initial stages in many other languages; especially in Arabic countries. Thus, it is worthy of
\end{abstract}


investigating the gaps related to such matters. This paper focuses on developing a mobile application that aims to enhance Arabic dyslexic students' reading skills. This study includes dyslexic students in Saudi Arabia who are eight to ten years old. The preliminary results showed promising prospects in such contexts for mobile learning, especially for dyslexic students. Furthermore, students showed very positive attitudes towards the proposed mobile application, leading to better engagement with learning Arabic.

\section{Keywords}

Dyslexia, Saudi Arabia, Mobile Application, M-Learning, Dyslexic Students

\section{Introduction}

It is noted that approximately up to $15 \%$ of the world's population may have dyslexia (Skiada et al., 2014); nonetheless, there is minimal research to see how mobile learning (mlearning) impacts people who have this common learning disability that affects reading and writing abilities.

Madeira et al. (2015) affirm that mobile technologies are a part of daily life and can help individuals have greater functionalism through learning aids for populations with special needs. In this case, phonological awareness, spelling, and rapid visual-verbal responses are all areas that dyslexia, a life-long condition, impacts, thereby requiring appropriate interventions to deliver results (Skiada et al., 2014).

Furthermore, graphic symbols and letters can prove challenging for the dyslexic populations to decode due to the inability to match corresponding sounds, place them in the correct sequence, and reverse or omit letters (Afrida et al., 2019).

With m-learning being the interaction between mobile computing and e-learning technologies, it is vital to know how it impacts users' experiences. In other words, how is their learning changed through uniquely engaging content that may include touchscreens? The International Dyslexia Association (IDA) affirmed that multisensory tools, such as the use of mobile applications, can aid learners to overcome visual, auditory, and kinesthetic-tactile deficits. For this reason, it is believed that a mobile application can be used to enhance memory and written language learning for students with dyslexia (Eroğlu et al., 2021).

Games are noted to be one means of giving students enhanced learning opportunities via mobile mediums. These individualized tools can aid memory, visual perception, auditory, 
language, reasoning, time orientation, space orientation, and fine motor skills. Two examples include Graphogame and Dyseggia, which present engaging content using an m-learning approach to decrease learning difficulties (Maderia et al., 2015). Therefore, a game-based interactive system is proposed by this study as an ideal solution for providing assistive technological intervention to improve reading within the Arab dyslexic population.

The following part of this paper is divided into four sections. Section 2 forms the related work to this presented paper; the issues faced in the Arabic language are contained in Section 3. The proposed solution is presented in section 4. The results and discourse of the experiments are provided in Section 5. Lastly, the conclusions and future work are drawn in Section 6.

\section{Literature Review}

Giving students access to supplemental materials, including technology-based exercises they can access anytime and anywhere. Thereby, it will aid in combating their specific problems (i.e., visual and auditory perception, difficulties with accurate and fluent word recognition, and poor spelling and decoding abilities) presented during the early stages of learning. El Kah et al. (2018) noted that a set of games for children with dyslexia is one means of improving the learning process. Madeira et al. (2015) stated that mobile applications are robust and highly functional while also being low-priced, making them excellent tools to support learning.

Much research confirmed that using a game-based interactive system is likely to enhance the learning opportunities for students with dyslexia. These findings are summarized in Skiada et al. (2014) and state, "Current research shows that games designed for mobile devices have considerable potential to encourage learning in the dyslexic population".

Khemaja and Taamaalah (2016) used a system technology that had adaptability and mobility as pros but lacked text-to-speech support and multimodal interface support and thus was less effective in engaging the learner's attention. Furthermore, Staels and den Broeck (2015) conducted a system technology that was noted to provide reliable measures of choice, naming, and spelling. Also, being reliable to assess a student's ability to read words; meanwhile, the noted cons were limited text-to-speech software and the absence of multimodal functional support. Finally, another system technology assessment study (Hall et al., 2014) was completed with complete flexibility. Still, there was limited discussion from the students' perspective, and it did not consider the student preferred learning style. 
More applications to address the issues faced by students with dyslexia, such as Developmental Visual and Developmental Letter Position Dyslexia, are needed (Burac et al., 2020). For example, Friedmann et al. (2012) conducted a study to look at 150 children referred to the Language and Brain Lab for more diagnoses related to their dyslexia. They prepared a test for the dyslexic students who have problems with the grapheme-to-phoneme conversion route through this process, misreading words as other words, migratable words, words with middle letter migration problems, and letter position dyslexia. The results indicated that $40 \%$ of letter position errors in migratable words that changed the letter form rarely occurred.

The use of games and applications in Arabic to assist students with dyslexia has been explored using verbal and non-verbal components (Al-Wabil et al., 2012). To further explore and diagnose the learning difficulties in Arab students with learning disabilities, Anoual and Lakhouaja (2015) designed mixed research to obtain information via questionnaires and interviews about Arabic learning disabilities in public primary schools on the east side of Morocco. Their study included a total of 2,304 students from third, fourth, fifth, and sixth grades, as well as 98 teachers, indicating minimal knowledge about how to meet dyslexic students' needs. In addition, this study showed that uneducated educators about dyslexia need assistive technology applications to assist in the instructional process (Almmazimi, 2013; Anoual and Lakhouaja, 2015).

It was noted that students who were able to purchase these learning applications were more motivated, whilst students who did not have access to the applications were limited, which means most students had access to these resources (Ismaili \& Ibrahmi, 2016). Through observations, a mixed-method study design relied on descriptive statistics and other data to show that future AT applications for teaching Arab students with dyslexia should have letter writing skills embedded in the application. Also, a multisensory approach teaches letter-sound comprehension and representative feedback (Al- dabaybah \& Jusoh, 2018). The results of the usability features for Arabic assistive technology for dyslexia indicated the increased performance of writing skills for students who used the prototype. Meanwhile, they showed the mere desire to use features already possible in applications. Still, they need to be further expanded beyond the initial prototype or created in mass for the public to use (Al-dabaybah \& Jusoh, 2018).

Similarly, Alghayth (2019) expressed differences in the use of AT for teaching students with learning disabilities, including mid-tech and high-tech applications, based on the needs of Saudi students with dyslexia. A total of 92 special education teachers in the first phase and five 
teachers in the second phase were interviewed to explore the effectiveness of AT applications and barriers as to how they are implemented in classrooms (Alghayth, 2019). There is a definite need for mobile-based AT applications to address and meet the needs of dyslexia students (Rello et al., 2012; Almekhafi \& Tibi; 2012; Alghayth, 2019).

Allafi and Newbury (2020) carried an intensive review about the current state of dyslexia in Saudi Arabia and was found that dyslexia needed to be investigated more thoroughly in Saudi Arabia.

Therefore, this paper sheds light on the importance of applying new tools for dyslexic students, as creating such mobile applications would enhance the outcome of these students.

\section{Arabic Language}

Background about the Arabic language is discussed in the following sections and the issues related to dyslexia in Arabic language. Lastly, the motivation of this study will be presented in the proposed solution.

\subsection{Background}

Arabic is written from right to left, and although it only contains 28 letters is relatively orthographically complex. Letters are written in a cursive style, with all 28 being able to be consonants. Meanwhile, three of them can also be called long vowels (و ي). Orthography or the typical spelling system does not represent the short vowels except those short vowels found in beginning readers' texts. These short vowels do not allow the vowel to repeat its name. Verbs are typically constructed from three-consonant roots used in verbal templates, whereas nominal templates are usually used for three-consonantal nouns. One also has to look at if the letter blends with the letter following it. Latest is based on the letter that precedes it and refers explicitly to the

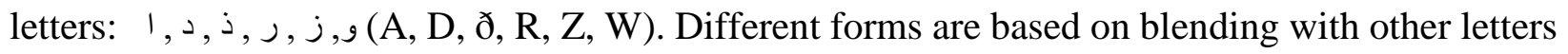
and positions.

The similar orthographic letters that share the same shape $(+, \dot{+}, \dot{-}, \dot{-})$ can cause dyslexia signs to manifest. Moreover, the letters (جح) share the same form, and the position of the dots is the only difference between them. Alamri and Teahan (2017) noted the problems that dyslexic students may face in differentiating between letters such as ' $દ$ ') "ghyn" (and letter 'ع') "ayn"). These letters have similar forms and different sounds. Therefore, when dyslexic students write these 
words, there are various errors made. The most common mistakes include omitting letters, adding letters, substituting letters, and transposing letters (Alamri et al., 2017).

\subsection{Problems Addressed in the Proposed Mobile Application}

There are multiple problems associated with Arabic letters. Understanding these problems can assist in better meeting the needs of dyslexic learners and create assistive devices to aid in reading skills.

1. Letter position dyslexia (LPD) is also called transposition of letters; it occurs when letters are transposed. These are typically the middle letters with beginning and final letters remaining in the correct position. A specific example of this can be found in "يكبتون" (YAKBETWN being written as "يكتبون" YAKTEBWN). Such a transposition would change the meaning from the pent up to what they write. Other target words can result in new words being created because of letter position errors. This event can be "جهاز" seen when a ligated letter moves to a position after a non-ligating letter (like JEHAZ being written as "جاهز" JAHEZ. The meaning of the former word is 'device', while the latter means 'ready', in which the $\mathrm{H}$ alternates between middle-ligating and initial/middle non-ligating forms). With the same letter being in different shapes and positions, transposing middle letters in a word while keeping the original letterforms creates an orthographically illegal sequence.

2. Developmental visual dyslexia (DVD) is visual errors involving substitutions, omissions, and additions of the letter (Friedmann et al., 2012). For example, omission of letter occurs if the student writes the word "منزل" MANZEL, which means House instead of "كنازل" MANAZEL which means Houses. Another example is "كتان" KETAN which means linen when they meant to write "كتاب" KETAB, which means a book, which is an example of the substitution of letters. Finally, the addition of letter occurs when, for example, instead of writing "ولد" WALAD, which means a boy, they write "والد" Waled, which means a father.

These abovementioned errors create mixed messages and further increase students' problems as dyslexic individuals.

In the app, steps were taken to assist with Developmental Visual Dyslexia. Friedmann and Haddad-Hanna (2012) discussed how developmental LPD causes many errors in which middle letters are transposed, thereby creating other existing words. The previously discussed litigated 
letters are also of concern here too. To assist with these abovementioned problems (i.e. LPD and DVD), features were built into the application to help.

\section{Proposed Method}

Previous research was used to acquire the top system features to include in this system. Al-dabaybah and Jusoh (2018) noted that the following components in assistive technologies are needed to support dyslexic populations. First, Simple design: Since many dyslexic students cannot recognize a specific icon's purpose without great mental effort, it is essential to design an application or other assistive technology with this in mind. Navigation should be possible via a simple design.

Students should be able to navigate between colours, options, and words easily. However, navigation can be difficult for dyslexic students, so including an arrow to directly move forward or backward is a problematic design feature. Instead of having only the needed arrow on the screen is better or even choose to have the program designed to proceed following student input, which the system has automatically.

Designing the identity of a home icon is one way to address this problem. In addition, being mindful of not including too many shapes or colours is essential, so these should be limited to only a few primary colours. No more than two images should be layered in the interface also to encourage understanding rather than confusion. Finally, design an application with fewer main menu options and appear full screen even on mobile devices.

Second, Audio support. Students with dyslexia need to hear the words; consequently, having an audio feature is vital. Providing audio with each image and text, if possible, is very important.

Third, providing feedback to the students during the learning process; is very important so students are aware of their mistakes and can self-correct them as part of the learning process. There is also some choice built-in, so students can choose the words that the system reads to them. Since reading the words correctly may be uncommon for these students, including simple words, encouraging sounds, and feedback to help immediately correct misconceptions. The audio format included will also help extrinsically motivated students; for example, they may hear clapping. Again, feedback in these forms is vital. 
Based on the abovementioned recommendations, this work proposes and implements a game-based application consisting of words to be used on mobile devices (i.e. both the IOS and Android Operating systems). Furthermore, the words used in this proposal should follow the frequency in the specific target language. In our case, we use the Arabic language. Hence, words were selected based on the students' curriculum.

\subsection{Participants}

This study contains participants who are in third to fifth grade. Those students have been diagnosed with dyslexia and are enrolled in public primary schools in Saudi Arabia. Eleven students between the ages of eight and ten participated in the study with self-reports disclosing no prior diagnosis of any learning disabilities.

\subsection{Application Development}

The proposed application is formulated with four games; each game targets a dyslexic issue, and each is distinct from another game. The first game is "Matching Up" and requires students to respond to a total of five questions. Each question presented in this introductory module has two texts and two corresponding images. Moving on, the second game, Word Construction, has students tap a specific balloon to choose a particular letter. There are two chances (trials) for each question with a total of ten questions. The Letter's Bank is in the third game. It aids students in avoiding letter order confusion. Students will respond to ten questions in this game as they select the ordering of letters to form words. The last game is based on Listening Words. It also contains ten questions.

Each game has common features, including the font, instructions, wording, and questioning format. The "Arial" font is used in each game; this is a simple font that is clear on all machines and easy to read. Madeira et al. (2015) noted that Arial is one of three fonts shown to help dyslexic individuals the greatest with reading performance. In addition, these fonts should be presented using a minimum font of -12 or 14 . The Arial font is used in the application with a heading size of 80 , a sub-heading of 30 , and a normal text size of 18 . In addition, the font colours are dark for the text with a light background. There are clear instructions given verbally and on the screen at the beginning of each game. These instructions aim to help each student to know how to play each game. The mobile application has forty unique words intentionally planned because they are part of students' curriculum. 
The general user interface design employed the C\# and Unity3D engine programming language. A home page and site structure are included for easy navigation. In addition, the Menu page has a suitable colour palette and nominal graphics that are created without distracting stimuli.
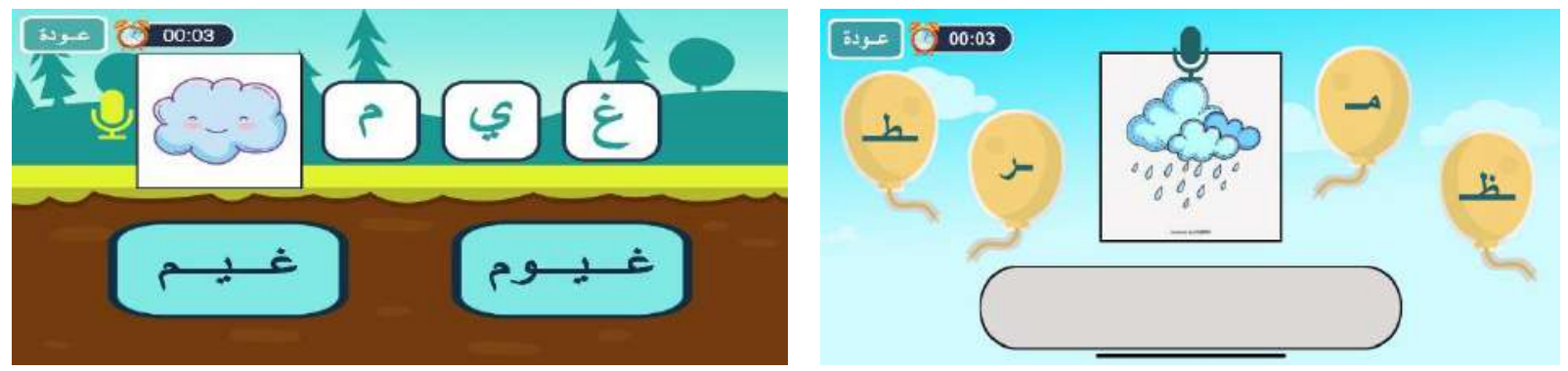

Figure 1: Screenshots of the Proposed Games used in the Study

\section{Results}

This study aims to evaluate the benefits of applying m-learning solutions to dyslexic students specifically. In general, participants showed significant enthusiasm toward the application, which led to a better preference in using a mobile device to practice and complete tests.

Using this application rather than paper and pencil type tests aids in maintaining focus, avoiding distractions, and targeting attention towards learning via a touchscreen device. The students with dyslexia noted differences, and while the data is preliminary, it is anticipated that the participants' scoring is improved. These observations support documented research on the issue.

Following the experimental phase, results were gathered and analyzed. Most of the students demonstrated high performance based on their score achievements. They no longer needed constant reading assistance, and their word recognition had become more instantaneous and less labour-intensive. Most of the participants shared these common results. Progress was noted in words recognition and phonological decoding. Students gained experience and familiarity with the application's text layout and developed greater confidence in utilizing the embedded features. Students were overwhelmingly excited to participate in this learning experience using the application. Presenting the learning in a game-like fashion made it entertaining and meaningful for them to participate in the abovementioned activities. 
Their responses to the application indicate a very favourable response to m-learning for students with dyslexia and show how beneficial the process improves their reading skills.

\section{Conclusion}

Given the potential benefits of a mobile application for dyslexic students, we designed a mobile application to improve students' fundamental learning skills through advanced technology (m-learning). A total of 11 students who were between the ages of eight and ten participated in the study. The proposed application is formulated with four games; each game targets a dyslexic issue, and each is distinct from another game. Each game has common features, including the font, instructions, wording, and questioning format. There are clear instructions given verbally and on the screen at the beginning of each game. The obtained results show that most of the students demonstrated high performance based on their score achievements. Progress was noted in words recognition and phonological decoding. Presenting the learning in a game-like fashion made it entertaining and meaningful for them to participate. Their responses to the application indicate a very favourable response to m-learning for students with dyslexia.

The findings presented in this study support the results in the field, especially the studies related to Arabic dyslexic students using m-learning techniques. It is concluded that such technology improves the outcome of students with dyslexia and making them more confident, especially in the classroom. In future work, we will extend this to a bigger focused group of students. It is noted that the progress is needed to be investigated more thoroughly; therefore, more questionnaires and observation would be applied to teachers, students, and their guardians. 


\section{REFERENCES}

Afrida, N., Mahriza, R., Rahmah, M., \& Santi, N. E. (2019). Visual and Cognitive Media: The Language Acquisition of Children with Dyslexia in Aceh. International Journal on Language, Research and Education Studies, 3(1), 112-126. https://doi.org/10.1109/ICSGRC.2018.8657536

Al-dabaybah, B. \& Jusoh, S. (2018). Usability features for Arabic assistive technology for dyslexia. ICSGRC. doi://DOI:10.1109/icsgrc.2018.8657536.

Alghayth, A. \& Mohammed, K. (2019). The use of assistive technology with students with several intellectual and developmental disabilities in Saudi Arabia. Teacher's perspectives. Graduate Theses and Dissertations. https://10.1145/27455512746644 .

Allafi, R., \& Newbury, P. (2020). REVIEWING THE CURRENT STATE OF ASSISTIVE TECHNOLOGICAL INTERVENTION FOR INCREASING READING SKILL OF DYSLEXIC PUPILS IN SAUDI ARABIA. 13th annual International Conference of Education, Research and Innovation (pp. 10054-10061). IATED. https://doi.org/10.21125/iceri.2020.2288

Al-Wabil, A., Al-Musaaed, H., \& Al-Sheha, M. (2012). Screening program for learning difficulties in Arabic speaking students: Design considerations for educational interfaces. Proceedings of the 1st International Workshop on Interaction Design in Educational Environments. pp. 67-78.

Anoual, E. \& Lakhouaja, A. (2015). Arabic learning disabilities in public primary schools: The case of east side of Morocco. International Journal of Pervasive Computing and Communications, 9(3), pp.209-226. https://doi.org/10.1108/IJPCC-07-2013-0016

Burac, M. A. P., \& Cruz, J. D. (2020, April). Development and Usability Evaluation on Individualized Reading Enhancing Application for Dyslexia (IREAD): A Mobile Assistive Application. In IOP Conference Series: Materials Science and Engineering (Vol. 803, No. 1, p. 012015). IOP Publishing. https://doi.org/10.1088/1757$\underline{899 X / 803 / 1 / 012015}$

El Kah, A. \& Lakhouaja, A. (2018). Developing effective educative games for Arabic children primarily dyslexics. Educ Inf Technology 23(6). https://doi.org/10.1007/s10639-018$\underline{9750-2}$ 
Eroğlu, G., Teber, S., Ertürk, K., Kırmızı, M., Ekici, B., Arman, F., ... \& Çetin, M. (2021). A mobile app that uses neurofeedback and multisensory learning methods improves reading abilities in dyslexia: A pilot study. Applied Neuropsychology: Child, 1-11. https://doi.org/10.1080/21622965.2021.1908897

Friedmann, N., \& Haddad-Hanna, M. (2012). Letter position dyslexia in Arabic: From form to position. Behavioural Neurology, 25(3), 193-203. https://doi.org/10.1155/2012/296974

Hall, T. E., Cohen, N., Vue, G., \& Ganley, P. (2015). Addressing learning disabilities with UDL and technology: Strategic reader. Learning Disability Quarterly, 38(2), 72-83. https://doi.org/10.1177/0731948714544375

Ismaili, J., \& Ibrahimi, E.H. (2016). Mobile learning as an alternative to assistive technology devices for special needs students. Education and Information Technologies, 22, 883-899. https://doi.org/10.1007/s10639-015-9462-9

Khemaja, M., \& Taamallah, A. (2016). Towards situation driven mobile tutoring system for learning languages and communication skills: Application to users with specific needs. Journal of Educational Technology \& Society, 19(1), 113-128.

Madeira, J., Silva, C., Marcelion, L., \& Ferreira, P. (2015). Assistive mobile application for dyslexia. Procedia Computer Science 64(1). https://doi.org/10.1016/j.procs.2015.08.535

Rello, L. \& Ballesteros, M. (2015). Detecting readers with dyslexia using machine learning with eye tracking measures. In Proceedings of the 12th web for ALL Conference. Association for Computing Machinery, 16(1). https://doi.org/10.1145/2745555.2746644

Skiada, R., Soroniati, E., Gardeli, A., \& Zissis, D. (2014). EasyLexia: A mobile application for children with learning difficulties. Procedia Computer Science, 27, 218-228. https://doi.org/10.1016/j.procs.2014.02.025

Staels, E., \& Van den Broeck, W. (2015). Orthographic learning and the role of text-to-speech software in Dutch disabled readers. Journal of Learning Disabilities, 48(1), 39-50. https://doi.org/10.1177/0022219413487407 